\title{
Comparative Analysis of Engineering Properties of Indus River Sand Concrete with Quarry Dust Concrete, District Jamshoro Sindh Pakistan
}

\author{
Mushtaque Ahmed Pathan ${ }^{1 *}$, MS. Maryam Maira ${ }^{2}$, Arif Ali Khaskheli ${ }^{3}$, Agha Jamshed Ahmed ${ }^{4}$
}

${ }^{1}$ Center for Pure \& Applied Geology, University Of Sindh, Jamshoro, Sindh Pakistan

${ }^{2}$ Institute of Environmental Engg \& Mgmt, Mehran University Jamshoro, Sindh Pakistan

${ }^{3}$ Material Engineer. Prof. Dr. G.B Khaskheli Engg. Lab Jamshoro Sindh Pakistan

${ }^{4}$ Department of Architecture, Mehran University Jamshoro, Sindh Pakistan

*Corresponding author: Mushtaque Ahmed Pathan

\section{Abstract}

This study shows the comparative analysis engineering, the physical and mechanical properties of river sand concrete with quarry dust concrete. The selected materials were batched by weight and volume. The water-cement ratio was opted as 0.50 1:2:4 for mix ratio was selected for the experimental investigation respectively. The specimens were cured for 7, 14, 21 and 28 days. For the purpose Slump, density and compressive strength tests were carried out. The river sand concrete showed better results and greater density and compressive strength than quarry dust concrete for all curing ages. The 28 days of curing, river sand concrete rise the required compressive strength by $36 \%$, whereas quarry dust concrete was less than the limit compressive strength by $12 \%$. Both river sand concrete and quarry dust concrete for the selected water/cement ratio and mix ratio has been found suitable for non-structural applications and lightly-loaded members where high strength is not a prerequisite.

Keywords: River Sand, Quarry Dust, Density, Compressive Strength, Concrete.

Copyright () 2021 The Author(s): This is an open-access article distributed under the terms of the Creative Commons Attribution 4.0 International License (CC BY-NC 4.0) which permits unrestricted use, distribution, and reproduction in any medium for non-commercial use provided the original author and source are credited.

\section{INTRODUCTION}

Pakistan is a developing country, the construction industry is highly rising Concrete is the most important construction material widely used for Sustainable development. The various source materials like river sand, quarry dust etc are used along with the fresh and recycled aggregates for rural and urban small and high rise buildings [12]. For the purpose to make concrete a more sustainable construction material, efforts are being taken towards research on utilization of alternative recycled materials as whole or partial replacement of constituent materials in concrete.

In Pakistan Sand and gravel represent the most widely consumed raw material after water, and between $60-75 \%$ of aggregate mined each year is used for making concrete [11]. Natural sand found in rivers and valleys has been commonly used as fine aggregate in concrete. Natural sand contains rounded or cubical particles with smooth surface texture which provide good workability in concrete [4]. Sand consists around $35 \%$ volume in a concrete mix [15]. The growing use of river sand as a raw material in production of concrete and other industrial applications indicates that depletion of deposits of natural sand is inevitable.Specially depletion in natural sand deposits, as well as the dredging and excavation processes used in obtaining natural fine aggregate, may cause negative environmental impact such as non-reversible landscape changes and threat to river ecosystems [12]. Considering to the environmental hazards associated with mining natural sand, concerned authorities in some areas have placed restrictions using measures such as legislation and taxation [6-9]. A most suitable alternative to natural sand in production of concrete is quarry dust, a by-product of rock quarrying. Quarry dust generally has particle sizes in the range of $0.05-5$ $\mathrm{mm}$ and forms around $20-25 \%$ of the total output of rock crushing $[6,10]$. Considerable volumes of quarry dust are produced by rock quarrying industries which cause environmental problems. Only a small percentage of the quarry dust is used as filler in wearing courses of asphalt pavements [9]. Use of quarry dust as an alternative to river sand in concrete can provide solutions to problems of waste management, 
Mushtaque Ahmed Pathan et al, Saudi J Civ Eng, Apr, 2021; 5(3): 74-78

environmental degradation and depletion of natural resources.

Experiments have been performed on use of quarry dust as total or partial replacement of river sand in concrete. For 28 days of curing, partial replacement of fine aggregate with $20-50 \%$ quarry dust content resulted to optimum compressive strength of concrete for several mix ratios and water/cement ratios [1-6]. Engineers have also used quarry dust as total replacement of sand in concrete. Quarry dust concrete for curing age of 28 days resulted higher compressive strength than river sand concrete $[6,7,8]$. while, a few studies showed lower compressive strength for quarry dust concrete in comparison with river sand concrete . Results on workability and density of quarry dust concrete are also different. This study compared the workability, density and compressive strength of quarry dust concrete with river sand concrete using the simmillar mix ratio and water/cement ratio. The simmillar quantity and type of cement, water and coarse aggregate were used in this study.

\section{MATERIALS AND METHODS Constituent Materials}

O P C (Ordinary Portland cement) of grade 42.5R manufactured to [20] standards was used. River sand and quarry dust were used as the fine aggregates used in the experimental investigation. River sand was dredged from Bholari riverr located in Jamshoro, Sindh province Pakistan while quarry dust was obtained from a quarry plant in the same vicinity. Crushed limestone aggregates of $20 \mathrm{~mm}$ nominal size was obtained from a quarry plant in same area and used as coarse aggregate. River water was used for washing the aggregates, as well as mixing and curing the concrete specimens.

\section{Testing of Aggregates}

The physical \& engineering properties including particle size distribution of the fine aggregates were determined. Generally tested physical properties of the both fine and coarse aggregates were specific gravity and density. Fineness modulus was determined for both river sand and quarry dust, alongwith aggregate impact and Los Angeles abrasion of the crushed limestone were tested.

\section{Preparation and Testing of Concrete Specimens}

C M R (Concrete mix ratio) was batched by weight $\&$ volume. The mix ratio and water-cement ratio selected for the investigation were 1:2:4 and 0.55, respectively. Mix ratio 1:2:4 is a specified prescribed mix which correlates to normal concrete strength [14]. Two separate groups of concrete specimens were prepared: mix containing $100 \%$ quarry dust as fine aggregate and another mix containing $100 \%$ river sand which served as content. No additives were used. The constituent materials were mixed manually. The cement and aggregates were first thoroughly mixed in dry state. Water of calculated quantity was gradually added to the dry mixture with continuous mixing. Concrete cubes of size $150 \times 150 \times 150 \mathrm{~mm}$ were prepared and cured. Sample specimens were put in the moulds for 24 hours to set before being demoulded and cured. The specimens were cured by immersion in a water tank for $7,14,21$, and 28 days respectively.

The slump cone test of fresh concrete, density of hardened concrete, and compressive strength of hardened concrete were tested and observed. Slump, density and compressive strength tests of the specimens were carried out in accordance with [3, 23] and [4, respectively. Density and compressive strength results were obtained for the concrete cubes at 7, 14, 21, and 28 days of curing. The density and compressive strength are represented by the average values of three concrete cubes for each curing age.

\section{RESULTS AND DISCUSSION Aggregates}

Sieve analysis or particle size distribution of river sand and quarry dust are shown in Fig. 1. The coefficient of curvature, $\mathrm{Cc}$ of river sand is 0.96 and the uniformity coefficient, $\mathrm{Cu}$ of river sand is 2.11 . The obtained values for quarry dust are 0.8 and 5.45, respectively. A well-graded soil has a $\mathrm{Cu}$ value of 5 or more and a $\mathrm{Cc}$ value between 1 and 3 [15]. The values show that the river sand has a small range of particle size whereas the quarry dust has a wider range of particle sizes. Both aggregates fall into zone 2 of the grading requirements for fine aggregates and are suitable for producing concrete mix [10]. 


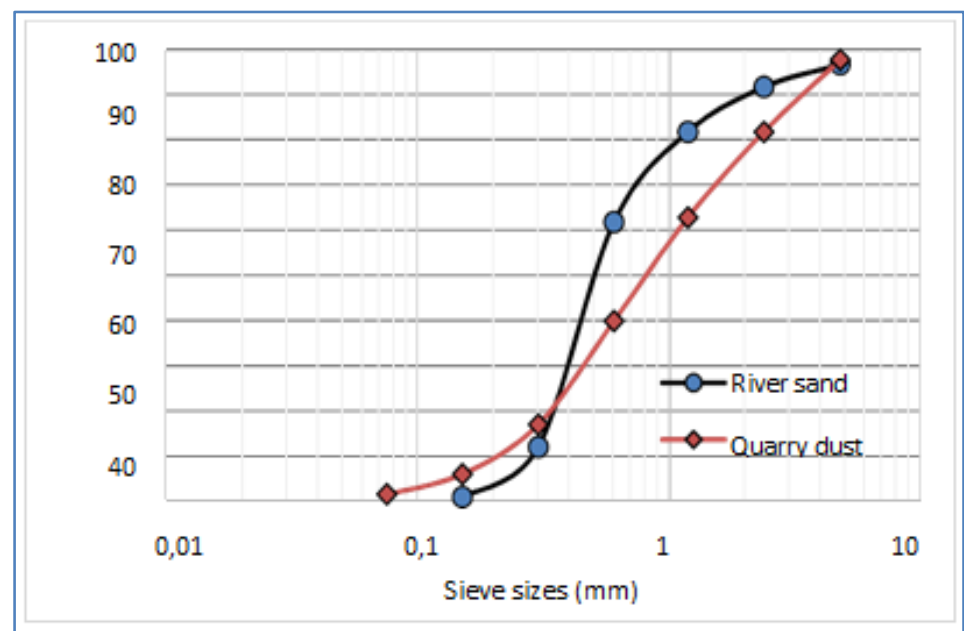

Fig-1: Particle size distribution curves for river sand and quarry dust

After the engineering experiments the obtained results of physical properties of the fine aggregates are given in Table 1, while the physical and mechanical properties of the coarse aggregate are given in Table 2 . The experimental values obtained for specific gravity of the aggregates were within the range for normal weight aggregates although quarry dust slightly exceeded the maximum limit stated in Neville and Brooks [7]. It should be noted that the permissible limits for specific gravity given in Tables 1 and 2 are not strict requirements for aggregates, but only represent the range for specific gravity of most normal weight aggregates used in preparing concrete. The bulk densities of the river sand, quarry dust and limestone are similar to values mentioned in previous investigations [9]. Fineness modulus noted for the fine aggregates indicate that river sand has relatively finer grains whereas quarry dust has coarser grains.

Table-1: Physical properties of aggregates

\begin{tabular}{|c|c|c|c|}
\hline Property & River sand & Quarry dust & Acceptance limit for concrete \\
\hline Specific gravity & 2.64 & 2.76 & $2.6-2.8[4,27]$ \\
\hline Fineness modulus & 2.54 & 2.96 & $2.2-3.2[4,29]$ \\
\hline Density $\left(\mathrm{kg} / \mathrm{m}^{3}\right)$ & 1570 & 1360 & - \\
\hline
\end{tabular}

Table-2: Physical and mechanical properties of coarse aggregate

\begin{tabular}{|c|c|c|}
\hline Property & Granite & Acceptance limit for concrete \\
\hline Specific gravity & 2.68 & $2.6-2.8[4,27]$ \\
\hline Density $\left(\mathrm{kg} / \mathrm{m}^{3}\right)$ & 1545 & - \\
\hline Aggregate impact value $(\%)$ & 15.10 & $25-45 \%[4,30]$ \\
\hline Los Angeles abrasion value $(\%)$ & 18.30 & $30-50 \%[4]$ \\
\hline
\end{tabular}

\section{Slump}

The quarry dust concrete and river sand concrete shoed slump test values of $80 \mathrm{~mm}$ and $60 \mathrm{~mm}$, respectively. And, fresh concrete mix of quarry dust concrete showed lower workability than river sand concrete for 1:2:4 mix ratio and water-cement ratio of 0.55 . The higher slump interposed for quarry dust may be due to higher sand content in quarry dust. Since the water content and cement content were constant, workability is anticipated to be lower in the concrete mix containing finer particles of fine aggregate. The quarry dust used in the study has higher percentage of coarse sand grains than river sand. Increase in fines content generally indicates to lower slump if the water content remains the same. Finer particles having higher surface area which requires more amount of water for wetting. The slump test result of both quarry dust concrete and river sand concrete fell within the range of
25-100 mm, indicating medium workability [13].

Density

In Fig. 2 the graph shows the density results of river sand concrete and quarry dust concrete. The bulk density of normal weight concrete usually lies between ranges from $2200-2600 \mathrm{~kg} / \mathrm{m}^{3}$ [5]. The density of all the specimens fall within the range of normal weight concrete. The densities increase with curing age, with 7 days correlating to the lowest density and 28 days having the highest density. There has been an increase in $7.6 \%$ between the densities of the 7-day and 28-day curing age of river sand concrete. And for the quarry dust concrete, the corresponding increase was $4.8 \%$. The increase in the density is attained to compaction effect of hydration process on the internal matrix of the concrete specimens due to curing. 


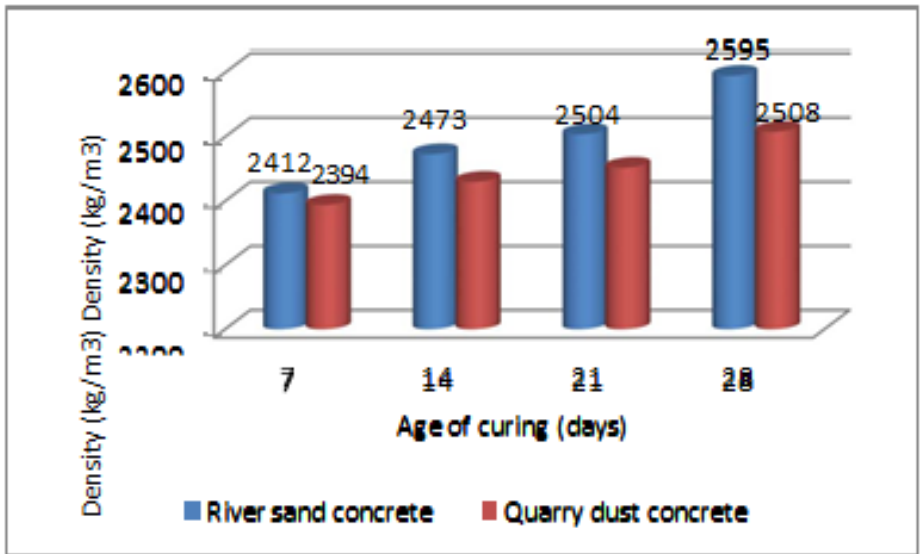

Fig-2: Density development of concrete specimens with age of curing

The proportion of silt/clay particles in quarry dust compared with river sand. Presence of very fine particles in aggregate trends to interact with the bond between cement paste and aggregate, which is the cause of reduction in strength.

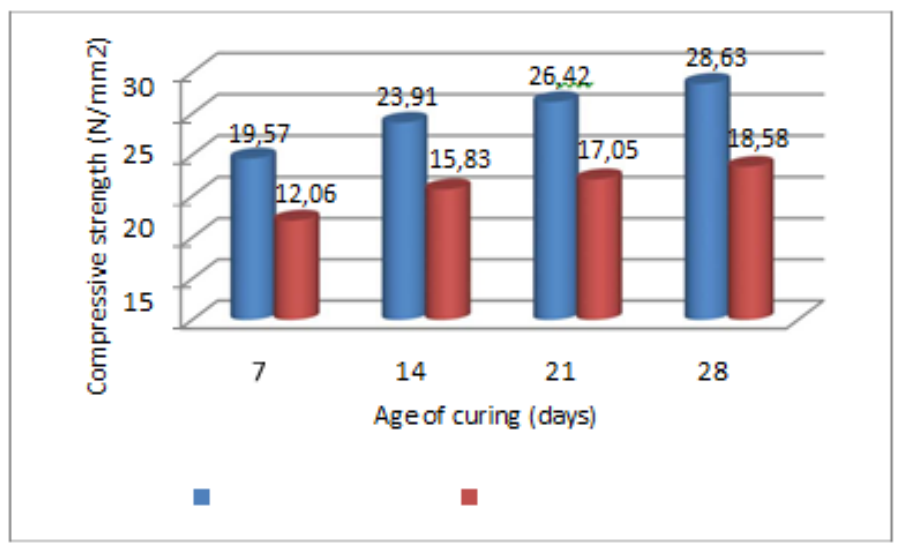

Fig-3: Compressive strength development of concrete specimens with age of curing

\section{CONCLUSION}

The observed properties of river sand concrete and quarry dust concrete have been comparatively analyzed accordingly slump, density and compressive strength. For the 1:2:4 mix ratio and 0.55 water-cement ratio, river sand concrete showed higher density and compressive strength than quarry dust concrete. While, quarry dust concrete has more workability. Both observed results of river sand concrete and quarry dust concrete can be applied in non-structural projects and lightly-loaded projects where high strength is not a rudiment. The river sand concrete is also suitable for batching and production of normal reinforced concrete.

\section{REFERENCES}

1. Abdullah, J. D. K. L., Ali, N., Mohamed, R. N., \& Muâ, M. (2018). The effect of quarry dust with cement by-products on properties of concrete. Malaysian Journal of Civil Engineering, 30(3).

2. Balamurugan, G., \& Perumal, P. (2013). Behaviour of concrete on the use of quarry dust to replace sand-an experimental study. IRACST-Engineering Science and Technology: An International Journal
(ESTIJ), 3(6).

3. Balamurugan, G., \& Perumal, P. (2013). Use of quarry dust to replace sand in concrete-An experimental study. International Journal of Scientific and Research Publications, 3(12), 1.

4. Febin, G. K., Abhirami, A., Vineetha, A. K., Manisha, V., Ramkrishnan, R., Sathyan, D., \& Mini, K. M. (2019). Strength and durability properties of quarry dust powder incorporated concrete blocks. Construction and Building Materials, 228, 116793.

5. Ilangovana, R., Mahendrana, N., \& Nagamanib, K. (2008). Strength and durability properties of concrete containing quarry rock dust as fine aggregate. ARPN Journal of Engineering and Applied Sciences, 3(5), 20-26.

6. Kankam, C. K., Meisuh, B. K., Sossou, G., \& Buabin, T. K. (2017). Stress-strain characteristics of concrete containing quarry rock dust as partial replacement of sand. Case studies in construction materials, 7, 66-72.

7. Kapgate, S. S., \& Satone, S. R. (2013). Effect of quarry dust as partial replacement of sand in concrete. Indian streams research journal, 3(5), 18 . 
8. Lohani, T. K., Padhi, M., Dash, K. P., \& Jena, S. (2012). Optimum utilization of Quarry dust as partial replacement of sand in concrete. Int. J. Appl. Sci. Eng. Res, 1(2), 391-404.

9. Mir, A. H. (2015). Improved concrete properties using quarry dust as replacement for natural sand. International Journal of Engineering Research and Development, 11(3), 46-52.

10. Pathan, M. A., Ahmed, R., \& Maira, M. (2019). Study of Coarse Aggregate Characteristics on Strength Properties of High Performance Concrete Using Chemical Admixtures.

11. Pathan, M. A., Lashae-Ri, R. A., \& Maira, M. (2018). Geotech Properties of Petaro Crushing Plants Coarse \& Fine Aggregates used in Concrete Asphalt in Road \& Building Construction, District Jamshoro Sindh, Pakistan. International Journal of Engineering Science, 17863.
12. Pathan, M. A., Lashari, R. A., Maira, M., Abbasi, S. A., \& MUET, J. (2018). Study of Engineering Properties of Bholari Sand Kotri District Jamshoro Sindh Pakistan. International Journal of Engineering Science, 18010.

13. Sakthivel, P. B., Ramya, C., \& Raja, M. (2013). An innovative method of replacing river sand by quarry dust waste in concrete for sustainability. CONTRIBUTORY PAPERS, 241.

14. Shyam Prakash, K., \& Rao, C. H. (2016). Study on compressive strength of quarry dust as fine aggregate in concrete. Advances in Civil Engineering, 2016.

15. Sukesh, C., Krishna, K. B., Teja, P. S. L. S., \& Rao, S. K. (2013). Partial replacement of sand with quarry dust in concrete. International Journal of Innovative Technology and Exploring Engineering (IJITEE), 2(6), 254-258. 